Article

\title{
Inclusion of 5-Mercapto-1-Phenyl-Tetrazole into $\beta$-Cyclodextrin for Entrapment in Silane Coatings: An Improvement in Bronze Corrosion Protection
}

\author{
Cecilia Monticelli ${ }^{1, *(\mathbb{D})}$, Giancarlo Fantin ${ }^{2}$, Graziano Di Carmine ${ }^{2}$, Federica Zanotto ${ }^{1}(\mathbb{D}$ and \\ Andrea Balbo ${ }^{1}$ D \\ 1 Centro di Studi sulla Corrosione e Metallurgia “A. Daccò”, Dipartimento di Ingegneria, \\ Università di Ferrara, 44121 Ferrara, Italy \\ 2 Dipartimento di Scienze Chimiche e Farmaceutiche, Università di Ferrara, 44121 Ferrara, Italy \\ * Correspondence: mtc@unife.it; Tel.: +39-0532-455136
}

Received: 23 July 2019; Accepted: 8 August 2019; Published: 10 August 2019

\begin{abstract}
The corrosion protection of coatings can be reinforced by the addition of entrapped corrosion inhibitors. $\beta$-cyclodextrin $(\beta-C D)$ can form inclusion complexes with small inhibiting organic molecules that, when entrapped in coatings, allow the inhibitor release and adsorption at corrosion initiation sites. In this paper, several Nuclear Magnetic Resonance (NMR)-based experiments (e.g., Complexation-Induced Shifts (CIS), NMR titration, Diffusion-Ordered Spectroscopy (DOSY)) were performed to study the stability and geometry of a complex formed by $\beta$-cyclodextrin with 5-mercapto-1-phenyl-tetrazole (MPT). The complex was also detected by Electrospray Ionization (ESI) mass spectrometry and characterized by Fourier Transform Infrared (FTIR) spectra. Its influence on the protectiveness of a silane coating against bronze corrosion was evaluated in plain (AR) and concentrated (ARX10) synthetic acid rain, under different exposure conditions. In particular, the time evolution of the polarization resistance values during 20 days in ARX10 and the polarization curves recorded at the end of the immersions evidenced a higher protectiveness of the coating with the $\beta-C D-M P T$ complex in comparison to that containing only MPT or only $\beta-C D$. The cyclic AR spray test carried out on coated bronze coupons with cross-cut scratches evidenced the absence of underfilm corrosion starting from the scratches only in the complex-containing coating.
\end{abstract}

Keywords: corrosion protection; smart coatings; inclusion complex; complex stability; bronze

\section{Introduction}

The corrosion protection of an organic coating depends largely on the intrinsic barrier properties of the polymeric film towards oxygen, water, and aggressive species, but can be reinforced by entrapped corrosion inhibitors [1-3]. In the case of bronze artworks exposed outdoors, commercial coatings such as Incralac ${ }^{\circledR}$ and Soter ${ }^{\circledR}$ contain benzotriazole (BTA) that operates in the dual functions of an inhibitor of bronze corrosion and an anti-UV additive [4]. In these coatings, the inhibitor dissolves in the electrolyte (in the rain) and penetrates through the coating, so producing an inhibited solution that exerts a protective action at the coating/metal interface. In general, the positive influence of direct inhibitor addition in coatings may be limited by solubility problems, by a decrease in barrier properties and adherence to the substrate, and by the rapid leaching of small inhibitor molecules induced by rainfalls, so determining a fast drop of the overall protection performance [5].

In recent years, great efforts were devoted to overcoming these problems and increasing the coating durability by encapsulating corrosion inhibitors in coatings through the adoption of suitable carriers, which make them more compatible with the coating network [6,7]. Different carrier types were 
investigated, such as inhibitor-filled porous particles, or nanocapsules, coated by polyelectrolytes [8-10] or layered anion-exchange particles containing intercalated corrosion inhibiting anionic species [11]. The former polyelectrolyte-coated carriers can release inhibitor molecules due to local variations of solution $\mathrm{pH}$ linked to the onset of corrosion phenomena, while the latter carriers with intercalated inhibiting anionic species limit the access of aggressive anions, such as chlorides, to the metal substrate and release corrosion inhibiting species by ion-exchange phenomena.

Beside these carriers, cyclodextrins (CD) were also used to host corrosion inhibitors due to their complexing capability towards small organic molecules with corrosion inhibition properties. Cyclodextrins (CDs) [12] are water-soluble macrocyclic oligosaccharides consisting of at least six $\alpha$-D-glucopyranose units linked via $\alpha(1-4)$ glycosidic bonds. The most common ones contain 6,7 and 8 glucopyranose residues and are known as $\alpha-, \beta-$, and $\gamma-C D$, respectively. CDs are among the most widely used host molecules thanks to their unique and specific structure that creates an internal cavity that is less hydrophilic than the external aqueous environment and therefore able to accommodate a large variety of hydrophobic molecules inside it [13]. The strong propensity of CDs to form inclusion complexes has been exploited not only for the production of smart coatings for corrosion protection, but also in many other fields of science, for example, as drug transport systems, [14], to increase the solubility of some chemical species [15], in separation technology [16], and in other areas [17].

Addition of complexes of $\alpha$ - and $\beta$-CDs with dibenzylthiourea (DBT) in acid solutions improved the corrosion resistance of carbon steel due to the enhanced solubility of the complexes in comparison to that of DBT alone [18]. The controlled release of BTA from $\beta$-CD-BTA complexes was investigated in order to achieve effective bronze corrosion protection in chloride solutions. The use of the complex instead of pure BTA was intended to reduce the toxicity of the additives used for corrosion protection [19]. Moreover, complexes of $\beta$-CD and $\gamma$-CD with mercaptobenzothiazole (MBT), mercaptobenzimidazole (MBI), mercaptobenzimidazole sulfonate, and thiosalicylic acid [20-23] were incorporated in coatings and improved the corrosion resistance of $\mathrm{Al}$ alloys and zinc. In fact, these complexes represent a reservoir of corrosion inhibitor molecules that, at the onset of corrosion phenomena and in correspondence of regions of coating delamination, tend to adsorb on the metal surfaces, shifting the complexation equilibrium towards the release of further inhibitor molecules.

In this research, the effective formation and the stability of a complex between $\beta-C D$ and 5-mercapto-1-phenyl-tetrazole (MPT) (Figure 1) were assessed. Among non-toxic corrosion inhibitors [24-26], MPT was chosen because of its outstanding inhibiting properties towards copper and bronze corrosion [27-29]. Its complex with $\beta$-CD was incorporated in a 3-mercapto-propyltrimethoxy-silane (PropS-SH) coating, and the protectiveness of the obtained coating was assessed on bronze during both immersions in concentrated acid rain and exposures to alternated acid rain spray. These tests were also performed on plain silane coating and coatings with only $\beta-C D$ or only MPT additions. For the continuous immersion tests, thin sub-micrometric silane films prepared by the dip coating method were used, in order to better differentiate their protectiveness. During the alternated acid rain spray test, the self-healing properties were assessed on thicker coatings (about $5 \mu \mathrm{m}$ ) produced by spraying after introduction of cross cut scratches. Spraying and brushing are the application methods most commonly adopted by restorers [30] and produce coatings more representative of those actually applied in the field.

It is important to stress that according to occupational hazard tests, the silane formulations here investigated were less toxic to restorers than Incralac ${ }^{\circledR}$ (as both pure product and ready to use $30 \%$ solution in nitro diluent) [31]. 
<smiles>Oc1c(-c2ccccc2)c(-c2ccccc2)c(O)c(-n2nnnc2S)c1-c1ccccc1</smiles>

(a)

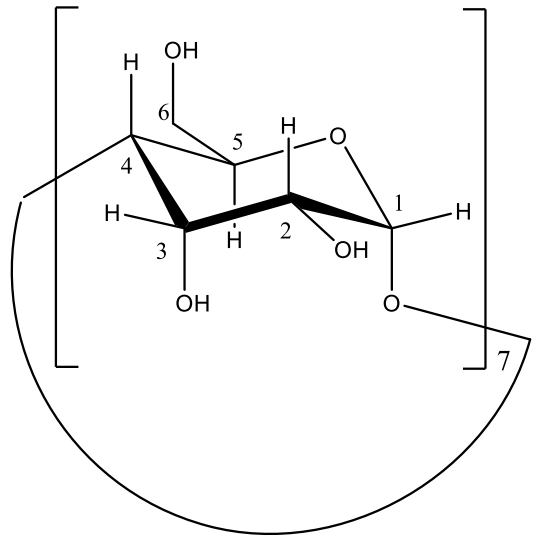

(b)

Figure 1. Molecular structure of (a) 5-mercapto-1-phenyl-tetrazole (MPT) and (b) $\beta$-cyclodextrin $(\beta-C D) . \beta-C D$ is a $C D$ type constituted by 7 glucopyranoside units linked by 1,4 glycosydic bonds.

\section{Materials and Methods}

\subsection{Chemicals, Aggressive Environment and Alloy}

All reagents and solvents used in this study were purchased from commercial sources. In particular, the chemicals used for the inhibitor complex and the coating production were $\beta$-cyclodextrin $(\beta-C D, \geq 97 \%$ purity), 5-mercapto-1-phenyl-tetrazole (MPT, 98\% purity), and 3-mercapto-propyl-trimethoxy-silane (PropS-SH, purity 95\%), all purchased from Sigma-Aldrich (Darmstadt, Germany).

The coating protectiveness was tested on as-cast bronze with composition $91.9 \mathrm{Cu}, 2.4 \mathrm{Sn}, 1.0 \mathrm{~Pb}$, $\mathrm{Zn} 2.9,0.8 \mathrm{Sb}$, wt.\%, and a microstructure reproducing those of Renaissance bronze artefacts with cored dendrites of $\mathrm{Cu}$-solid solution characterized by $\mathrm{Sn}$ and $\mathrm{Sb}$ local enrichment and also including $\mathrm{Pb}$ globules in the interdendritic spaces, as reported in previous papers [29,31-33].

Concerning the environments where the coating protectiveness was assessed, the cyclic acid rain (AR) spray test was performed using a synthetic AR, prepared with Sigma-Aldrich ACS reagents, according to the recipe reported in [34] and containing the following ion concentrations: $\mathrm{SO}_{4}{ }^{2-}$ $1.90 \mathrm{mg} \cdot \mathrm{L}^{-1}, \mathrm{Cl}^{-} 1.27 \mathrm{mg} \cdot \mathrm{L}^{-1}, \mathrm{NO}_{3}^{-} 4.62 \mathrm{mg} \cdot \mathrm{L}^{-1}, \mathrm{CH}_{3} \mathrm{COO}^{-} 0.23 \mathrm{mg} \cdot \mathrm{L}^{-1}, \mathrm{HCOO}^{-} 0.05 \mathrm{mg} \cdot \mathrm{L}^{-1}$, $\mathrm{NH}_{4}{ }^{+} 1.05 \mathrm{mg} \cdot \mathrm{L}^{-1}, \mathrm{Ca}^{2+} 0.34 \mathrm{mg} \cdot \mathrm{L}^{-1}, \mathrm{Na}^{+} 0.53 \mathrm{mg} \cdot \mathrm{L}^{-1}$, and $\mathrm{pH} 4.35$. During the electrochemical tests, accelerated corrosion conditions were obtained by using tenfold concentrated AR (ARX10, $\mathrm{pH}=3.3$ ) at $30{ }^{\circ} \mathrm{C}$.

\section{2. $[\beta-C D-M P T]$ Complex Stability Analysis}

\subsubsection{Nuclear Magnetic Resonance (NMR) Measurements}

The NMR spectra were recorded in $\mathrm{D}_{2} \mathrm{O}$ solution using $5 \mathrm{~mm}$ tubes, at $296 \mathrm{~K}$, with a Varian Mercury Plus 400 (Palo Alto, CA, USA), operating at $400\left({ }^{1} \mathrm{H}\right)$ and $100 \mathrm{MHz}\left({ }^{13} \mathrm{C}\right)$, respectively. The chemical shifts were referenced to the DOH signal: $\delta(\mathrm{H}) 4.65 \mathrm{ppm}$. The 1D-Rotating frame Overhauser effect spectroscopy (ROESY) NMR spectra were acquired using standard pulse sequences from the Varian library. The relaxation delay between successive pulse cycles was $1.0 \mathrm{~s}$.

The Diffusion-Ordered Spectroscopy (DOSY) experiments were performed using the Dosy Bipolar Pulsed Pair STimulated Echo (DBPPSTE) pulse sequence [35] from the Varian library, using 15 different gradient values varying from $2 \%$ to $95 \%$ of the maximum gradient strength. A $500 \mathrm{~ms}$ diffusion time was chosen, and the gradient length was set to $2.0 \mathrm{~ms}$. The analysis of all NMR spectra was performed with MestreNova (by Mestrelab Research, S.L., Santiago de Compostela, Spain), version: 6.0.2-5475 and for the DOSY analysis, the Baysian DOSY transform from MestreNova, version: 6.0.2-5475 was used. 


\subsubsection{H NMR Titration}

The following two solutions were prepared in $\mathrm{D}_{2} \mathrm{O}$ : Solution A: $2.8 \mathrm{mM}$ MPT. Solution B: $2.8 \mathrm{mM}$ MPT and $12.0 \mathrm{mM} \beta$-CD. A $0.8 \mathrm{~mL}$ aliquot of solution A was placed in a $5 \mathrm{~mm}$ NMR tube. A measured amount of solution $B$ was added, changing the molar fraction of the host to about $0,0.39,0.71,0.98$, $1.21,1.68,2.02$ and 2.29. Spectra were recorded after each addition. The chemical shift variation of the guest signals was collected, and the binding constants $\beta$ (as log K) were calculated by the curve fitting method [36] using the commercial HypNMR2008 [37] program (details are given in the Supplementary Information (SI) file).

\subsubsection{Electrospray Ionization (ESI) Mass Spectra}

ESI mass spectra were obtained using an LCQ Duo (ThermoQuest, San Jose, CA, USA) in negative-ion mode. Instrumental parameters: capillary voltage $-10 \mathrm{~V}$, spray voltage $4.50 \mathrm{kV}$, mass scan range was from m/z 100 to $2000 \mathrm{amu}$, for 30,000 ms scan time; $\mathrm{N}^{2}$ was used as the sheath gas. The samples were injected into the spectrometer through a syringe pump at a constant flow rate of $8 \mathrm{~mL} / \mathrm{min}$.

\subsubsection{Fourier Transform Infra-Red (FTIR) Analysis}

Diffuse reflectance FTIR spectra were recorded on $\beta$-CD-MPT complex powder and on MPT and $\beta$-CD powders, as references. The instrument used was a Thermo-Scientific Nicolet iS50 spectrometer (Thermo Fisher Scientific, Waltham, MA, USA), operating in dry $\mathrm{CO}_{2}$-free air flow generated by a Balston 75-52 unit. It was equipped by a deuterated triglycine sulfate (DTGS) detector, which allowed for the investigation of the $4000-400 \mathrm{~cm}^{-1}$ wavenumber region with a resolution of $4 \mathrm{~cm}^{-1}$.

\subsection{Silane Coating Production}

Silane hydrolysis was carried out by dissolving PropS-SH in a hydroalcoholic solution (90/5/5 v/v ethanol/water/PropS-SH), acidified to $\mathrm{pH} 4$ by the addition of some drops of diluted sulphuric acid solution, according to the methodology refined in previous research works [29,38-40].

Plain PropS-SH coatings were directly produced from this solution after $24 \mathrm{~h}$ room-temperature ageing. The coating additives were introduced in the aged silane hydroalcoholic solution; in particular, $3 \mathrm{~mL}$ aqueous solutions of either $5.94 \mathrm{mM}$ MPT or $5.94 \mathrm{mM} \beta-\mathrm{CD}$ or $5.94 \mathrm{mM} \beta-\mathrm{CD}+5.94 \mathrm{mM} \mathrm{MPT}$ were added to $30 \mathrm{~mL}$ of silane solution, so that the final molar concentration of the additives in the coating formulations was $0.54 \mathrm{mM}$. These solutions were sonicated for $3 \mathrm{~min}$ and then applied to the substrate either by dip coating $(1 \mathrm{~h}$ immersion and then fast withdrawal, reaching a final coating thickness of about $300 \mathrm{~nm}$; for accelerated electrochemical tests) or by spraying (to reach a final constant coating specific weight of $6 \pm 1 \mathrm{~g} \cdot \mathrm{m}^{-2}$ and thickness of $5 \pm 1 \mu \mathrm{m}$; for cyclic AR spray tests). Finally, the coatings were cured for $24 \mathrm{~h}$ at $50{ }^{\circ} \mathrm{C}$. This low temperature curing was compatible with the requirements for cultural heritage bronze artworks.

\subsection{Silane Coating Protectiveness}

Electrochemical tests were performed under accelerated corrosion conditions, that is in ARX10 ( $\mathrm{pH}$ 3.3) at $30^{\circ} \mathrm{C}$, on thin dip-coated bronze electrodes. As a reference, tests were also carried out on bare bronze electrodes.

The evolution of corrosion conditions was monitored over 20 days of immersion by Electrochemical Impedance Spectroscopy (EIS, performed by a PARTSTAT 2273, from Ametek, Berwyn, PA, USA) tests performed at intervals, under the following experimental conditions: corrosion potential $\left(E_{\mathrm{cor}}\right) \pm$ $10 \mathrm{mV} \mathrm{rms}, 10 \mathrm{kHz}-1 \mathrm{mHz}$ frequency range and 10 frequencies/decade. Polarization resistance $\left(R_{\mathrm{p}}\right)$ values were estimated from the spectra in the Nyquist form, as the difference between the limit of the real part of the impedance at frequency tending to $0\left(R_{\mathrm{p}}{ }^{\prime}\right)$ and the solution resistance $\left(R_{\mathrm{s}}\right)$ value $\left(R_{\mathrm{p}}=R_{\mathrm{p}}{ }^{\prime}-R_{\mathrm{s}}\right)$ [40]. $R_{\mathrm{p}}$ values are inversely proportional to the corrosion currents $\left(i_{\mathrm{cor}}\right)$, as indicated 
by the Stern and Geary relationship [41]: $R_{p}=\frac{B}{i_{c o r}}$, with B a constant depending on the Tafel slopes of the anodic and cathodic polarization curves. The time evolutions of average $R_{\mathrm{p}}$ and $E_{\text {cor }}$ values were obtained from triplicate experiments.

Ohmic drop-compensated polarization curves were collected at the end of the 20 day immersion period. Separate anodic and cathodic potential scans, always starting from $E_{\text {cor }}$, were carried out at a rate of $0.1667 \mathrm{mV} \cdot \mathrm{s}^{-1}$. These tests were performed in triplicate and representative curves were reported.

The self-healing capability of PropS-SH coatings was assessed by exposing coated coupons with cross cut scratches to a cyclic AR spray test at $35^{\circ} \mathrm{C}$ for 4 weeks. Each cycle consisted in $8 \mathrm{~h}$ spraying and $16 \mathrm{~h}$ waiting. During the test, the coupons were supported with an angle of $30^{\circ}$ from the vertical. Micrographs documented the extent of the final corrosion attack.

\section{Results}

\subsection{NMR Studies}

To verify the effective formation of a host-guest complex between $\beta-C D$ and MPT we mainly employed the NMR spectroscopy, already widely used to study inclusion complexes of CD [42-44].

The ${ }^{1} \mathrm{H}$ NMR spectrum in $\mathrm{D}_{2} \mathrm{O}$ of a sample containing an equimolar amount of $\beta-\mathrm{CD}$ and MPT showed induced chemical shifts $(\Delta \delta)$ for all the protons of the host as well as for most of the guest protons (Figure 2). The complexation-induced shifts (CIS) observed for the internal protons of $\beta-C D$ $(\mathrm{H} 3, \mathrm{H} 5)$ were remarkably larger than those displayed by the external ones $(\mathrm{H}-1, \mathrm{H}-2$, and $\mathrm{H}-4)$ (Table 1$)$, thus indicating that the guest likely interacts with the inner cavity of $\beta-C D$.

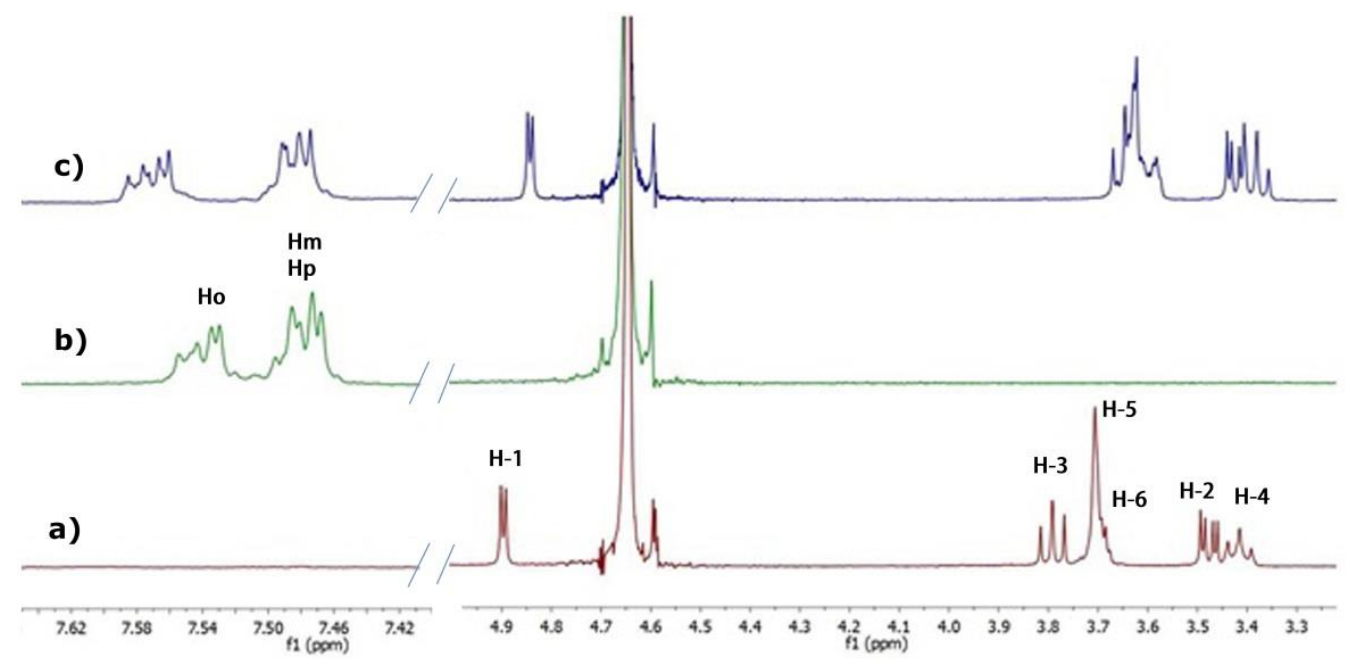

Figure 2. The ${ }^{1} \mathrm{H}$ NMR spectra in $\mathrm{D}_{2} \mathrm{O}$ for solutions of (a) $\beta-\mathrm{CD}$; (b) MPT; (c) equimolar amount of $\beta-C D$ and MPT.

Table 1. The ${ }^{1} \mathrm{H}-\mathrm{NMR}$ chemical shifts $(\delta, \mathrm{ppm})$ for $\mathrm{H}$ protons of $\beta-\mathrm{CD}$ alone, MPT alone, and complexation induced shifts $\left(\mathrm{CIS}=\delta_{\text {complex }}-\delta_{\text {free }}\right.$ ) of equimolar amounts of them in $\mathrm{D}_{2} \mathrm{O}$ at $23^{\circ} \mathrm{C}$.

\begin{tabular}{|c|c|c|c|c|c|c|c|}
\hline$\beta-C D$ & Protons & H-1 & H-2 & H-3 & H-4 & H-5 & H-6 \\
\hline$\delta$ alone & & 4.90 & 3.48 & 3.80 & 3.42 & 3.71 & 3.69 \\
\hline CIS & & -0.06 & -0.06 & -0.15 & -0.04 & -0.09 & -1.1 \\
\hline MPT & Protons & $\mathrm{H}-\mathrm{o}^{\mathrm{a}}$ & H-m ${ }^{a, b}$ & $H-p^{a, b}$ & & & \\
\hline$\delta$ alone & & 7.54 & 7.48 & 7.48 & & & \\
\hline CIS & & 0.04 & 0.01 & 0.01 & & & \\
\hline
\end{tabular}


The small CIS observed for the ortho-protons of the phenyl moiety of MPT (0.04 ppm, Table 1) was also particularly significant, indicating that a part of the phenyl ring of MPT entered into the cavity of $\beta$-CD. It is worthy of note that no new peaks appeared in the spectrum, signifying that the inclusion of MPT in $\beta-C D$ is a fast exchange process that takes place on the NMR timescale.

In order to gather information on the sites of binding we carried out a series of monodimensional ROESY-1D experiments [45] that provided only a small nuclear Overhauser effect (NOE) on the inner $\mathrm{H} 3$ proton of $\beta-\mathrm{CD}$ when ortho-H phenyl protons of MPT were irradiated.

The experimental observations collected up to this point were compatible with the inclusion structure of Figure 3, which was in rapid equilibrium with the two separate molecules. In fact, the large CIS exhibited by inner protons $\mathrm{H} 3$ and $\mathrm{H} 5$ of $\beta-\mathrm{CD}$ upon the addition of MPT clearly indicated a deep insertion of the host into the hydrophobic cavity of the $\beta$-CD. However, the lack of dipolar interactions between the ortho- and meta-protons of the aromatic ring of MPT and the H5 proton of $\beta$-CD excluded the complete insertion of the phenyl moiety into the $\beta$-CD cavity. On the other hand, the weak rotating-frame Overhauser effect (ROE) existing between the ortho-protons of MPT and the $\mathrm{H} 3$ proton of $\beta-\mathrm{CD}$ suggested that a partial insertion of the phenyl moiety of MPT occurred at the wide rim of $\beta-C D$. Finally, the upfield shift of the H- 6 protons of the $\beta-C D$ (see Table 1 ) could be justified by the partial protrusion of the guest (tetrazole moiety) from the narrow rim of the $\beta-C D$ (Figure 3) [46].

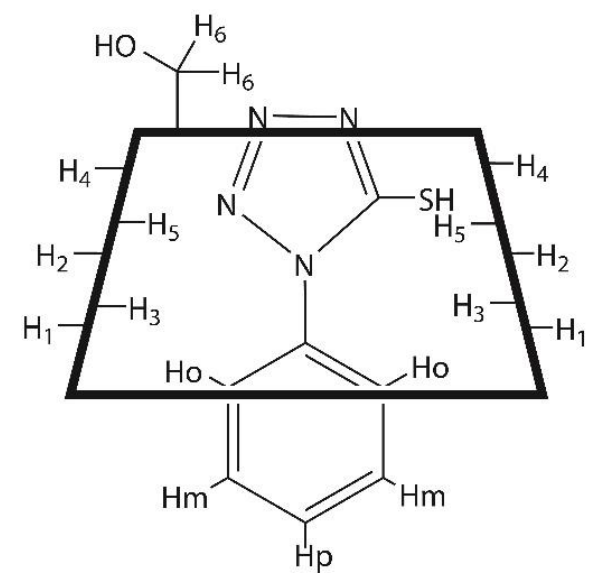

Figure 3. Proposed geometry for the inclusion of MPT into $\beta-C D$ as deduced from the CIS and ROESY-1D experiments.

To investigate the strength of complexation we carried out a ${ }^{1} \mathrm{H}$ NMR titration of MPT with $\beta-C D$ [36]. The procedure adopted in the titration allowed us to operate with a constant guest concentration $([\mathrm{MPT}]=$ constant $)$ during the whole experiment.

The binding isotherm relative to the ortho-protons of the phenyl moiety of MPT is depicted in Figure 4 . The value of the stability constant $\beta$ as $\log K_{\mathrm{a}}$ of the $\beta$-CD-MPT inclusion complex was calculated by the curve fitting method [36], using the commercial HypNMR2008 [37] program (details are given in SI) and was found to be equal to $2.93 \mathrm{M}^{-1}\left(K_{\mathrm{a}}=851 \mathrm{M}^{-1}\right)$.

The 1:1 stoichiometry of the complexation adequately described the binding data obtained from the NMR titration and, on the other hand, the physically unrealistic binding parameters (some negative $K_{\mathrm{s}}$ ) when the 1:2 or 2:1 models were applied to the NMR titration. This confirmed that the 1:1 stoichiometry was dominating in the investigated concentration range. The 1:1 stoichiometry of the complex was further confirmed by ESI-Mass Spectrometry (ESI-MS).

DOSY spectroscopy $[37,42-47]$ experiments were also carried out to confirm, qualitatively and quantitatively, the intermolecular interactions between MPT and $\beta-C D$ in solution. The DOSY technique allowed for the determination of the individual self-diffusion coefficients (D) in multicomponent systems that directly reflected the association behavior of the interacting species [48]. 


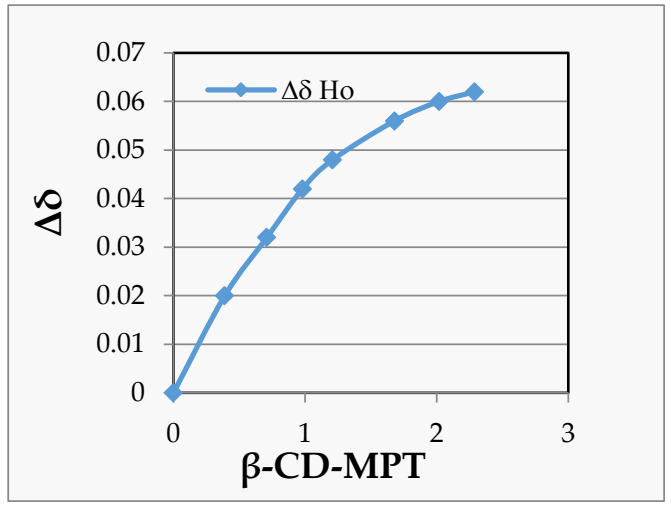

(a)

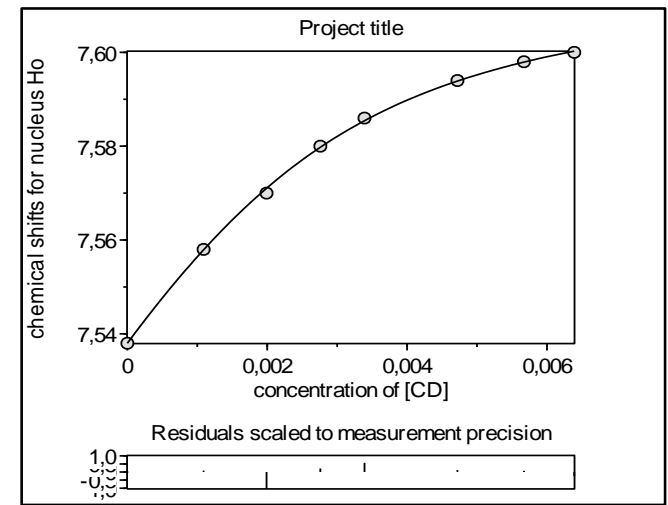

(b)

Figure 4. The ${ }^{1} \mathrm{H}$ NMR titration of MPT with $\beta-\mathrm{CD}$ : (a) Chemical shift change of the ortho-protons of the phenyl moiety of MPT with increasing $\beta-C D$ concentration. Positive values mean downfield shifts. The small complexation induced shift (CIS) observed for the ortho-protons of the phenyl moiety of MPT (0.04 ppm, see Table 1) was particularly significant, indicating that a part of the phenyl ring of MPT entered into the cavity of $\beta$-CD. (b) Curve-fitting analysis by the HypNMR2008 program.

The principle on which DOSY is based is very simple and can be summarized as follows: when the host and the guest are in the free state, they have their own diffusion coefficient that depends on their molecular weight and their shape. However, when they interact tightly together to form a complex, they behave as a single molecular entity and therefore should have the same diffusion coefficient $[48,49]$.

Taking into account the fact that we are studying a rapid equilibrium on the NMR time scale between bound and free guest molecules, the observed (measured) diffusion coefficient $\left(D_{\mathrm{obs}}\right)$ is the weighted average of the free and bound diffusion coefficients ( $D_{\text {free }}$ and $D_{\text {bound, }}$, respectively) and can therefore be used to calculate the bound fraction $p$ by using the following Equation (1):

$$
D_{\text {obs }}=p \cdot D_{\text {bound }}+(1-p) \cdot D_{\text {free }}
$$

which can be rearranged to yield:

$$
p=\frac{D_{\text {free }}-D_{\text {obs }}}{D_{\text {free }}-D_{\text {bound }}}
$$

where $p$ is the fraction of complexed substrate molecules.

After binding of a small guest molecule (MPT) to a large host molecule ( $\beta-\mathrm{CD})$ the diffusion coefficient of the host is not greatly perturbed, therefore, the diffusion coefficient of the host-guest complex can be assumed to be the same as that of the non-complexed host molecule [50].

Pseudo 2D DOSY spectra are shown in Figure 5. The f1 dimension represents the self-diffusion coefficient $(D)$ and the $\mathrm{f} 2$ dimension reports the chemical shift. The $\mathrm{f} 1$ is specific for each molecule, so the protons belonging to the same molecule appear in the same f1 row. The diffusion coefficients $(D)$ and the fraction of complexed MPT molecules $(p)$ measured at $23^{\circ} \mathrm{C}$ in $\mathrm{D}_{2} \mathrm{O}$ are reported in Table 2.

As expected, the $D$ value of encapsulated MPT $\left(4.87 \cdot 10^{-6} \mathrm{~cm}^{2} \cdot \mathrm{s}^{-1}\right)$ was lower than that of free MPT $\left(6.205 \cdot 10^{-6} \mathrm{~cm}^{2} \cdot \mathrm{s}^{-1}\right)$ (Table 2, Figure 5) thus proving that MPT is included in the $\beta$-CD cavity and diffuses more slowly. Recalling that the association constant, $K_{\mathrm{a}}$, for a 1:1 host-guest equilibrium of the type $\mathrm{H}+\mathrm{G} \rightleftarrows \mathrm{HG}$ is defined by:

$$
K_{\mathrm{a}}=\frac{[\mathrm{HG}]}{[\mathrm{H}][\mathrm{G}]}
$$


where $[\mathrm{H}],[\mathrm{G}]$, and $[\mathrm{HG}]$ are the equilibrium concentrations of the free host, free guest, and complex, respectively, Equation (3) can be rewritten as a function of the molar fraction [48] as:

$$
K_{\mathrm{a}}=\frac{p}{(1-p)\left([\mathrm{H}]_{0}-p[\mathrm{G}]_{0}\right)}
$$

where $\left[\mathrm{H}_{0}\right]$ and $\left[\mathrm{G}_{0}\right]$ are the total concentrations of the host and guest, respectively.

Lastly, inserting the value of the molar fraction just obtained from the DOSY experiments in the above Equation (4) we can calculate $K_{\mathrm{a}}$ by using the single-point procedure [51,52]. The association constant measured in this way was $654 \mathrm{M}^{-1}$ at $23^{\circ} \mathrm{C}$ (Table 2), and although the value obtained by the single-point approximation method results in large uncertainty, it is consistent with the corresponding value of $851 \mathrm{M}^{-1}$ estimated via NMR titration.

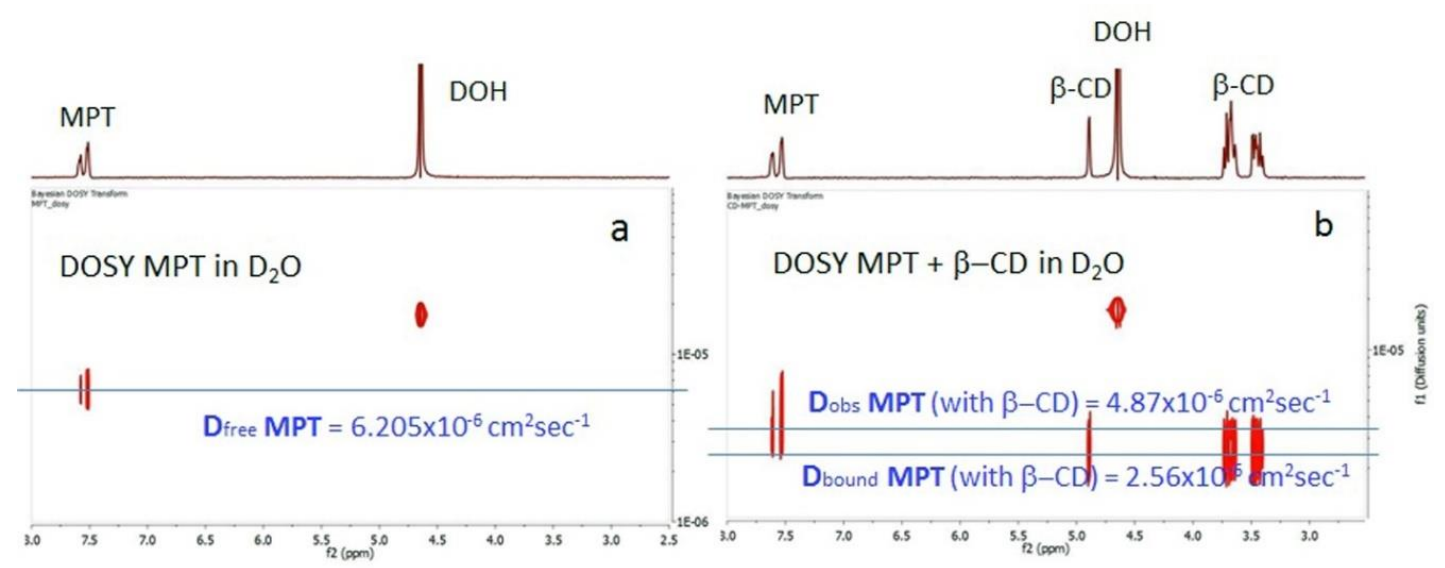

(a)

(b)

Figure 5. Pseudo 2D DOSY spectra of MPT (a) $1.5 \mathrm{mM}$; (b) in the presence of $\beta-\mathrm{CD} 1.4 \mathrm{mM}$ in $\mathrm{D}_{2} \mathrm{O}$, at $23^{\circ} \mathrm{C}$. (See Supplementary Information, SI, for details).

Table 2. Diffusion coefficients $\left(D, 10^{-6} \mathrm{~cm}^{2} \cdot \mathrm{s}^{-1}\right)$ related to the itemized protons of $\mathrm{MPT}_{\text {free }}$ (MPT alone $1.5 \mathrm{mM}), \mathrm{MPT}_{(+\beta-\mathrm{CD})}$ (MPT $1.5 \mathrm{mM}$ with $\left.\beta-\mathrm{CD} 1.4 \mathrm{mM}\right)$, and $\beta-\mathrm{CD}_{(+\mathrm{MPT})}$ (MPT $1.5 \mathrm{mM}$ with $\beta-\mathrm{CD} 1.4 \mathrm{mM})$, fraction of complexed MPT and $\beta-\mathrm{CD}$ molecules $(p)$ and association constant for the $\beta$-CD-MPT complex $\left(K_{\mathrm{a}}\right)$.

\begin{tabular}{|c|c|c|c|c|c|}
\hline Chemical Species & Proton (ppm) & $D^{\mathrm{a}, \mathrm{b}}$ & $D_{\text {average }}$ & $p_{\text {bound }}$ & $K_{\mathrm{a}}\left(\mathrm{M}^{-1}\right)$ \\
\hline \multirow{2}{*}{$\mathrm{MPT}_{(\text {free })}$} & $\mathrm{H}_{\mathrm{o}}(7.59)$ & 6.22 & 6.205 & 0 & - \\
\hline & $\mathrm{H}_{\mathrm{m}} / \mathrm{H}_{\mathrm{p}}(7.51)^{\mathrm{c}}$ & 6.19 & - & - & - \\
\hline \multirow{2}{*}{$\mathrm{MPT}_{(+\beta-C D)}$} & $\mathrm{H}_{\mathrm{o}}(7.62)$ & 4.88 & 4.87 & 0.36 & 654 \\
\hline & $\mathrm{H}_{\mathrm{m}} / \mathrm{H}_{\mathrm{p}}(7.52)^{\mathrm{c}}$ & 4.86 & - & - & - \\
\hline \multirow{3}{*}{$\beta-C D_{(+\mathrm{MPT})}$} & $\mathrm{H}_{\mathrm{m}} / \mathrm{H}_{\mathrm{p}}(7.52)^{\mathrm{c}}$ & 2.256 & 2.56 & 0.36 & - \\
\hline & $\mathrm{H}_{3} / \mathrm{H}_{5} / \mathrm{H}_{6}(3.67)^{\mathrm{c}}$ & 2.57 & - & - & - \\
\hline & $\mathrm{H}_{2} / \mathrm{H}_{4}(3.43)^{\mathrm{c}}$ & 2.55 & - & - & - \\
\hline
\end{tabular}

\subsection{ESI Mass Spectra}

In order to provide further confirmation of the formation of the $\beta$-CD-MPT inclusion complex, some ESI-MS experiments were conducted in aqueous solutions containing MPT and $\beta$-CD in the ratio 1:1, 1:2, and 2:1. In all cases, a base peak at $\mathrm{m} / \mathrm{z} 1311$ corresponding to a 1:1 host-guest complex was detected (Figure 6). 


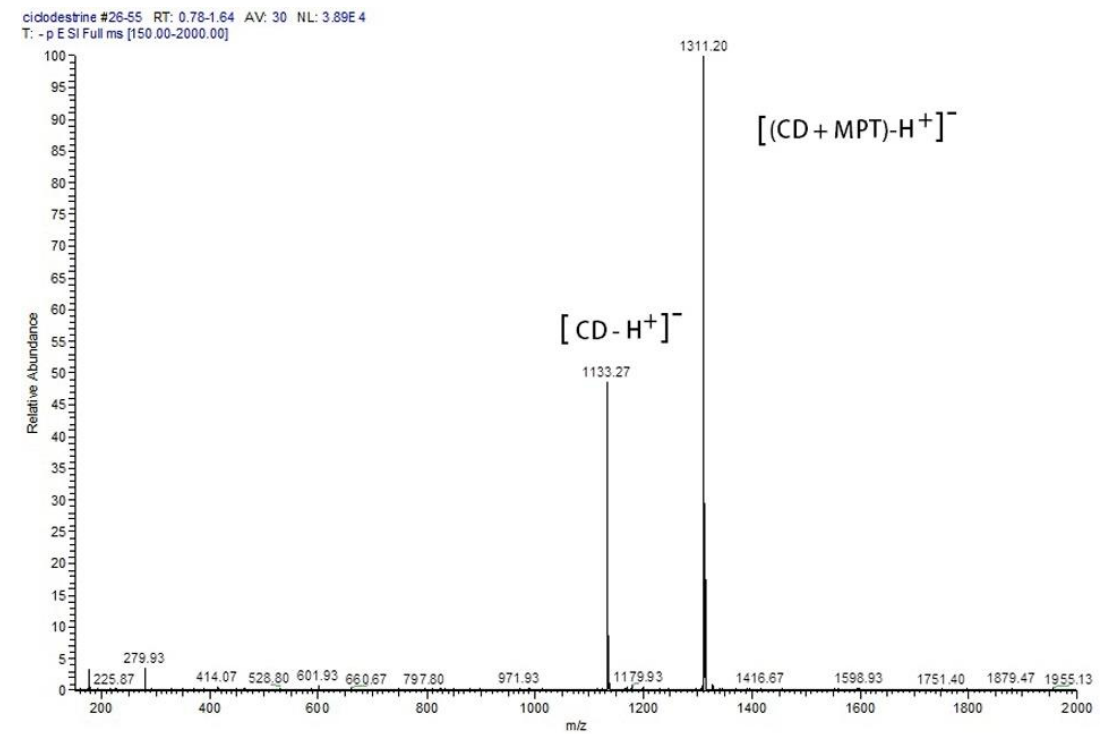

Figure 6. Electrospray negative-ion mass spectrum (ESI-MS) of a 1:1 $\beta$-CD-MPT aqueous solution that revealed a base peak corresponding to the 1:1 host-guest complex at m/z 1311 and a peak at m/z 1133 $(50 \%)$ relative to uncomplexed $\beta-C D$.

\subsection{FTIR Spectra}

The diffuse reflectance FTIR spectrum of the solid $\beta-C D-M P T$ complex precipitated from equimolar $\beta-C D$ and MPT aqueous solutions was recorded and compared to those obtained on pure MPT and $\beta$-CD. Figure 7 clearly shows that the spectrum of the complex almost completely overlapped that of $\beta-C D$, but two extra peaks at $1492 \mathrm{~cm}^{-1}$ and $1593 \mathrm{~cm}^{-1}$ occurred (as evidenced in the enlarged inset), which corresponded to intense bands of the MPT molecule and did not appear in the $\beta$-CD spectrum. According to X.R. Ye et al. [53], both peaks were connected to the C-C stretching of the phenyl ring in MPT and the former also corresponded to $\mathrm{N}-\mathrm{H}$ bending. These spectra further confirmed the complex formation.

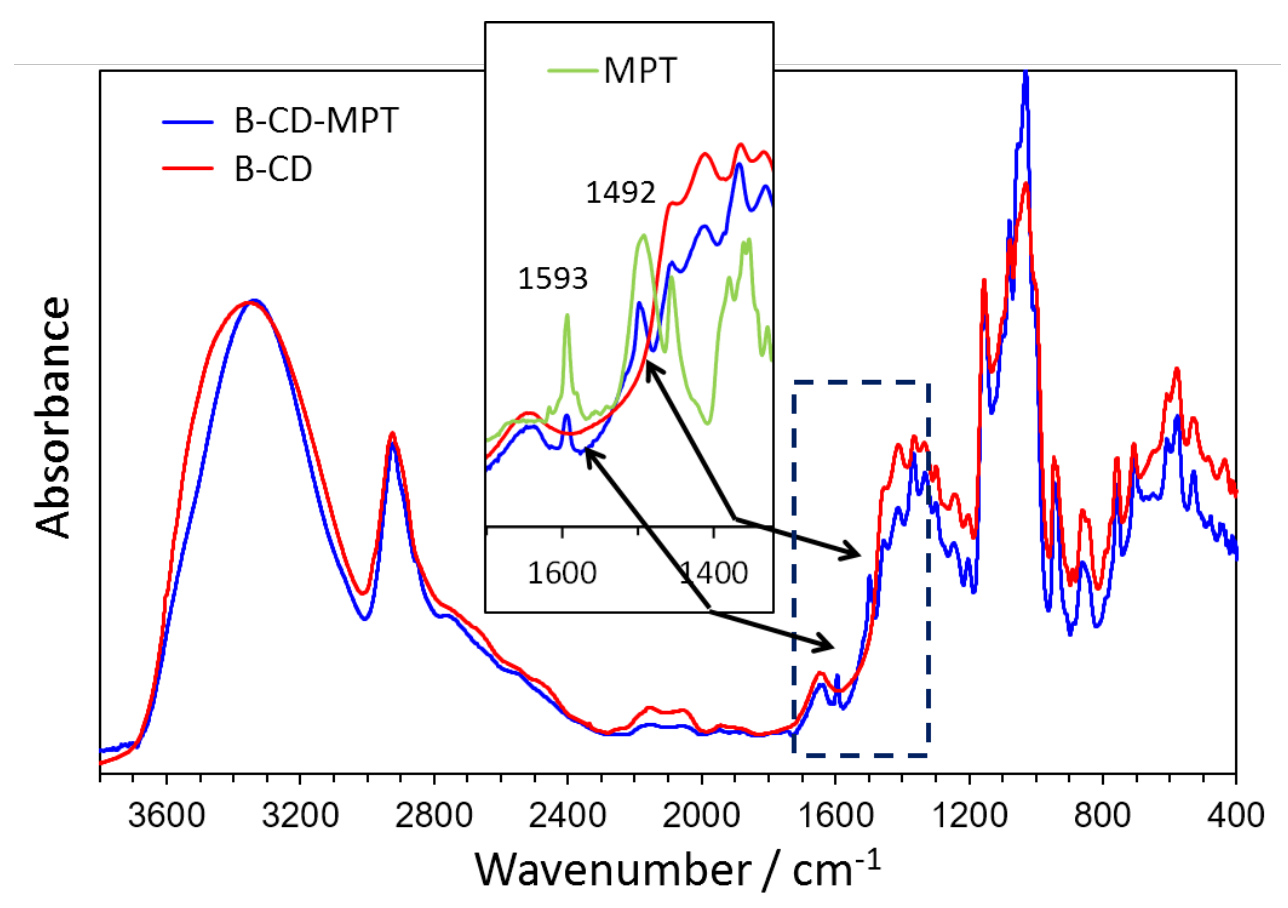

Figure 7. FTIR spectra of solid $\beta-C D-M P T, M P T$, and $\beta-C D$. 


\subsection{Electrochemical Tests}

These tests were performed on dip coated bronze electrodes in ARX10, because the association of the obtained thin coatings and the higher aggressiveness of the concentrated solution allowed for the differentiation of the coating protectiveness within the 20 day immersion period.

Figure 8 collects the time evolution of $R_{\mathrm{p}}$ and $E_{\text {cor }}$ values in this environment at $30^{\circ} \mathrm{C}$. For bare electrodes, high initial $R_{\mathrm{p}}$ values $\left(9.1 \mathrm{kohm} \cdot \mathrm{cm}^{2}\right)$ were obtained, which decreased quickly to about $1 \mathrm{kohm} \cdot \mathrm{cm}^{2}$ for immersions longer than $1 \mathrm{~h}$ and then increased again up to $4.6 \mathrm{kohm} \cdot \mathrm{cm}^{2}$ towards the end of the immersion period (Figure 8a). PropS-SH coatings showed much higher initial $R_{\mathrm{p}}$ values (almost $700 \mathrm{kohm} \cdot \mathrm{cm}^{2}$ ), which decreased by about 1 order of magnitude during the 20 days of immersion due to the slow penetration of the aggressive solution through the silane network. The addition of MPT to the silane solution determined rather low and constant $R_{\mathrm{p}}$ values, close to $20 \mathrm{kohm} \cdot \mathrm{cm}^{2}$. This behavior was not investigated but it is plausible that MPT interfered with the coating reticulation and/or a surface competitive adsorption between free MPT molecules on one side and the silanol and thiol groups of silane coatings on the other occurred, so impairing the coating adherence and performance. Instead, some improvements were achieved with the addition of $\beta-C D$, which due to its hydroxyl groups was likely capable of reacting with the silanol groups, so contributing to the silane network formation. Finally, a clear progression was observed after $\beta$-CD-MPT complex addition with high and rather constant $R_{\mathrm{p}}$ values (around $1 \mathrm{Mohm} \cdot \mathrm{cm}^{2}$ ). This suggests that beside the positive effect of $\beta-C D$, the release of MPT molecules from the $\beta-C D$ cavity could also play an important role in corrosion inhibition.

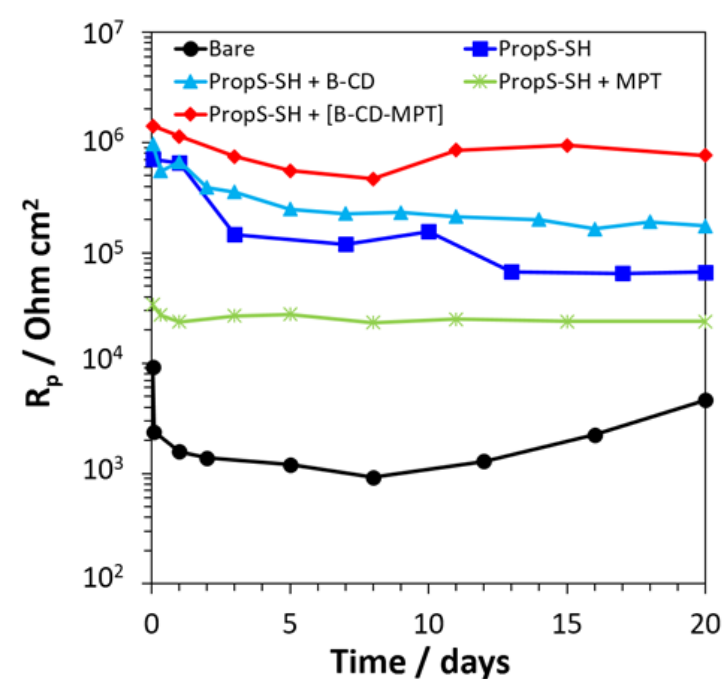

(a)

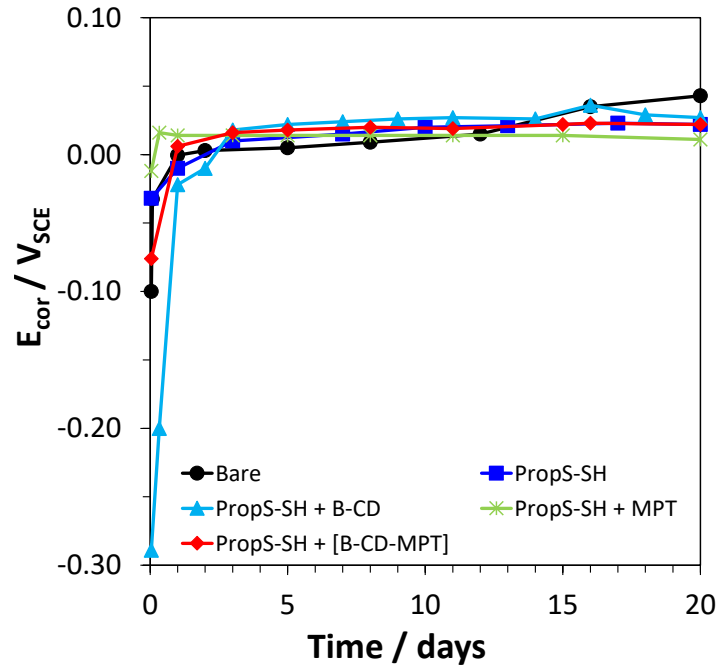

(b)

Figure 8. Polarization resistance $\left(R_{\mathrm{p}}\right)(\mathbf{a})$ and corrosion potentials $\left(E_{\text {cor }}\right)$ values $(\mathbf{b})$ measured during 20 days of immersion of bare and coated bronze electrodes in concentrated acid rain (ARX10) at $30{ }^{\circ} \mathrm{C}$.

The $E_{\text {cor }}$ values on bare electrodes evolved from $-0.100 \mathrm{~V}_{\mathrm{SCE}}$ after $1 \mathrm{~h}$ immersion to about $+0.043 \mathrm{~V}_{\mathrm{SCE}}$ after 20 days (Figure 8b). From previous research [54], it was found that this trend was the consequence of the degradation of the protective surface air-formed oxide film during the first half of the immersion period, which stimulated the cathodic reaction, with a consequent $E_{\text {cor }}$ shift towards nobler values. Then, in the second half of the immersion, the progressive accumulation of surface corrosion products induced a slight inhibition of the anodic process and further consequent $E_{\text {cor }}$ ennoblement. No significant $E_{\text {cor }}$ differences were detected in the presence of the coatings. In all cases, $E_{\text {cor }}$ increased to a certain extent during the initial 2 or 3 days of immersion, likely due to the evolution in the coating reticulation [39]. Then, they reached values in the range from 0.011 to $0.030 \mathrm{~V}_{\mathrm{SCE}}$, independently of the corresponding $R_{\mathrm{p}}$ values. 
The polarization curves recorded at the end of the 20 days of immersion on bare and coated electrodes are shown in Figure 9, while Table 3 reports the electrochemical parameters derived from these curves.

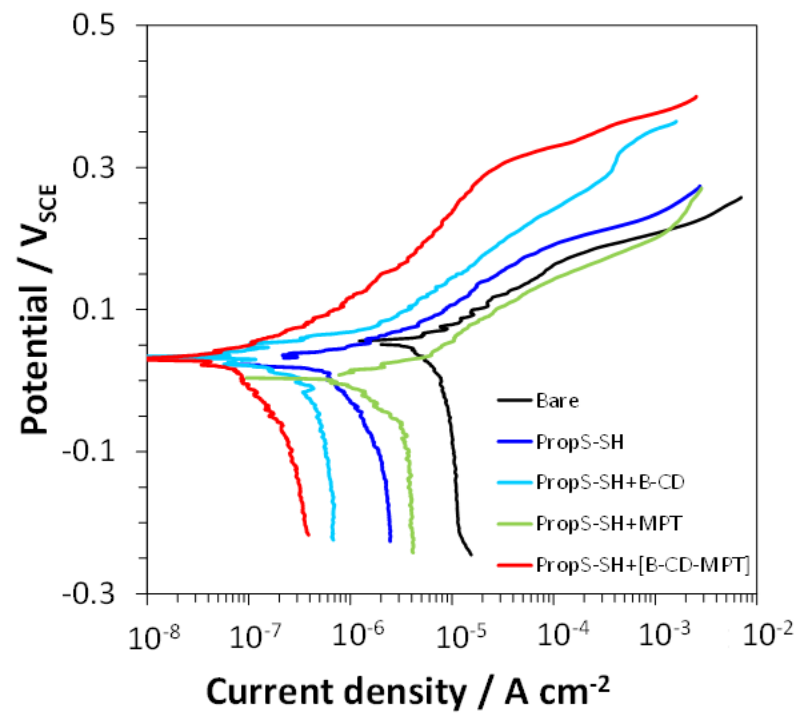

Figure 9. Polarization curves recorded on bare and silane (PropS-SH)-coated bronze specimens in the absence and in the presence of $\beta-C D, M P T$, or $\beta-C D-M P T$ complex, after 20 days of immersion in ARX10 at $30^{\circ} \mathrm{C}$.

Table 3. Corrosion potentials $\left(E_{\text {cor }}\right)$, corrosion current densities $\left(i_{\text {cor }}\right)$, and anodic Tafel slopes $\left(b_{\mathrm{a}}\right)$ obtained on bare and coated bronze specimens after 20 days of immersion in ARX10 solution. Protection efficiencies $(\eta)$ of silane coatings are also reported.

\begin{tabular}{ccccc}
\hline Coating Type & $\boldsymbol{E}_{\text {cor }} / V_{\text {SCE }}$ & $\boldsymbol{i}_{\text {cor }} / \boldsymbol{\mu A} \cdot \mathbf{c m}^{-\mathbf{2}}$ & $\boldsymbol{b}_{\mathbf{a}} / \mathbf{V}$ & $\eta / \%$ \\
\hline- & 0.055 & 8.3 & 0.090 & - \\
PropS-SH & 0.024 & 1.3 & 0.092 & 84 \\
PropS-SH + $\beta$-CD & 0.030 & 0.70 & 0.088 & 92 \\
PropS-SH + MPT & 0.008 & 2.8 & 0.093 & 66 \\
PropS-SH + $\beta$-CD-MPT & 0.029 & 0.15 & 0.101 & 98 \\
\hline
\end{tabular}

In particular, Table 3 collects the $E_{\text {cor }}$ and corrosion current $\left(i_{\text {cor }}\right)$ values, the anodic Tafel slopes, $b_{a}$, and the protection efficiency $(\eta)$ of the coatings, evaluated by the formula:

$$
\eta=\frac{i_{\text {cor }, \mathrm{b}}-i_{\mathrm{cor}, \mathrm{c}}}{i_{\mathrm{cor}, \mathrm{b}}} \times 100
$$

where $i_{\mathrm{cor}, \mathrm{b}}$ and $i_{\mathrm{cor}, \mathrm{c}}$ are the corrosion currents evaluated on bare and coated electrodes, respectively. The cathodic Tafel slopes, $b_{\mathrm{c}}$, which were not reported in Table 3 , were generally much higher than $b_{\mathrm{a}}$ and close to infinity.

Figure 9 and Table 3 evidence that the coatings protect the underlying alloy from corrosion at different degrees. The plain PropS-SH coating mainly hindered the cathodic reaction, so determining a slight reactivation of $E_{\text {cor }}$ in comparison to those of the bare electrodes, and afforded a final $\eta$ of about $84 \%$. In agreement with the $R_{\mathrm{p}}$ results, the addition of MPT to PropS-SH was detrimental to the coating protectiveness because it stimulated both the anodic and the cathodic reactions, suggesting a lower barrier effect of the coating and/or a lower surface adherence. In this case, the coating $\eta$ value decreased down to $66 \%$ (Table 3). Conversely, the addition of $\beta-C D$ or, even more, the $\beta-C D-M P T$ complex in the coatings determined a decrease in the anodic and cathodic currents and induced $\eta$ values of $92 \%$ and $98 \%$, respectively. In contrast with MPT, the complex proved to be beneficial to the 
coating performances, likely due to a higher compatibility of the external $\beta$-CD surface with the silane network and to the specific inhibition afforded by released inhibitor molecules as evidenced by the following test.

\subsection{Cyclic AR Spray Test}

The self-healing capability of the silane coatings connected to the inhibitor release and adsorption at corrosion sites was evaluated during four weeks of exposure of the coated specimens with cross cut scratches to cyclic AR spray.

At the end of the test (Figure 10), the bronze coupons evidenced that the PropS-SH coating was rather protective at a distance from the scratches, but obviously did not avoid the substrate corrosion in scratched areas from which in fact the underfilm corrosion propagated. This corrosion form and coating delamination were less evident in the presence of $\beta-C D$, suggesting that this substance also increased the coating adherence, so improving the overall coating protectiveness. However, again, it did not prevent corrosion in the scratches. The addition of MPT in PropS-SH could not avoid the spread of corrosion attacks from the scratches and induced a significant surface color change (a brightening). Only $\beta$-CD-MPT complex addition significantly enhanced the substrate corrosion resistance and completely suppressed corrosion in the scratches and underfilm. This behavior suggested a self-healing capability of this coating type in the case of coating defects and mechanical damages, so prolonging the coating effectiveness.

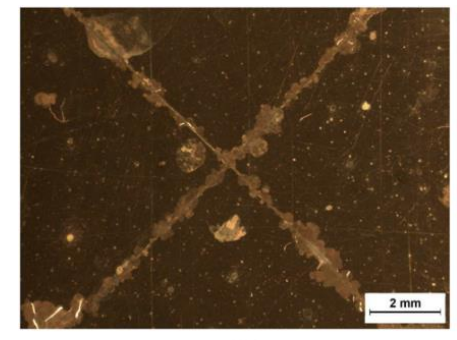

PropS-SH

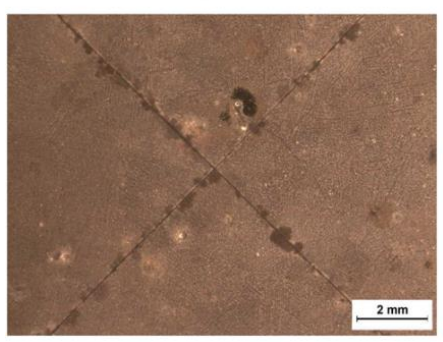

PropS-SH + MPT

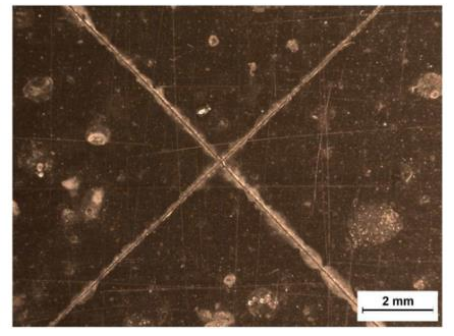

PropS-SH $+\beta-C D$

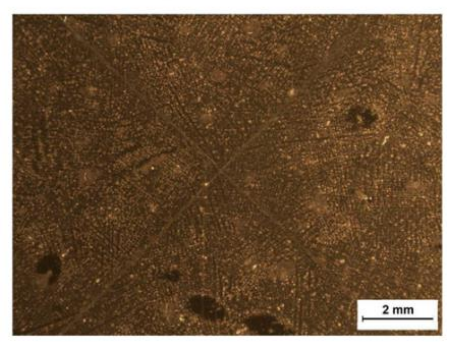

PropS-SH $+\beta-\mathrm{CD}-\mathrm{MPT}$

Figure 10. Surface aspect of cross-cut coupons at the end of a 4 week exposure to a cyclic acid rain (AR) spray test; only the PropS-SH coating containing the $\beta$-CD-MPT complex prevented the development of a corrosion attack starting from the scratches.

\section{Conclusions}

- The stability and the molecular structure of the host-guest $\beta$-CD-MPT complex was assessed by NMR, FTIR, and MS techniques.

- The analysis of the Complexation Induced Shifts suggested an inclusion structure of the complex, with partial insertion of the phenyl moiety of MPT at the wide rim of the hydrophobic $\beta-C D$ cavity and partial protrusion of the tetrazole moiety of the inhibitor from the narrow rim of the host cavity.

- According to the DOSY experiments, the stability constant of the $\beta-C D-M P T$ complex was $654 \mathrm{M}^{-1}$, in good agreement with the value of $851 \mathrm{M}^{-1}$ obtained by curve fitting the NMR binding isotherm. 
- $\quad$ The PropS-SH coating with entrapped $\beta$-CD-MPT complex exhibited an improved protectiveness $(\eta=98 \%)$ against bronze corrosion in comparison to plain PropS-SH $(\eta=84 \%)$ or PropS-SH containing only MPT $(\eta=66 \%)$ or $\beta-C D(\eta=92 \%)$.

- $\quad$ The PropS-SH coating with entrapped $\beta$-CD-MPT complex exhibited self-healing properties on bronze during exposures to cyclic AR spray at $35^{\circ} \mathrm{C}$.

Supplementary Materials: Supplementary materials are available online at http://www.mdpi.com/2079-6412/9/ 8/508/s1, Table S1: Parameters related to the titration, Figure S1: Variations of a portion of 1H NMR spectrum $(400 \mathrm{MHz})$ of MPT $2.8 \mathrm{mM}$ during its titration with $\beta-C D 12 \mathrm{mM}$ in D2O, the molar fractions of host are reported in Table S1, Figure S2: Stacked plot and computational analysis of the DOSY experiment of a sample containing MPT alone. MPT signal decays according to the gradients $(G)$ together with the corresponding graphical analysis of the data. The diffusion coefficients are indicated with the letter F, Figure S3. Stacked plot and computational analysis of the DOSY experiment of a sample containing MPT $+\beta-C D$. MPT signal decays according to the gradients $(G)$ together with the corresponding graphical analysis of the data. The diffusion coefficients are indicated with the letter F, Figure S4: Stacked plot and computational analysis of the DOSY experiment of a sample containing $\mathrm{MPT}+\beta-\mathrm{CD}$. $\beta-\mathrm{CD}$ signal decays according to the gradients $(\mathrm{G})$ together with the corresponding graphical analysis of the data.

Author Contributions: Conceptualization and Methodology, C.M., G.F., and A.B.; Formal analysis C.M., G.F., and A.B.; Investigation G.F., G.D.C., C.M., F.Z., and A.B.; Writing-Review and Editing C.M., G.F., C.M., F.Z., and A.B.

Funding: This research was carried out in the scope of the B-IMPACT project (project ID 1149) of the M-ERA.NET 2013 call, supported by the national funding organizations of the partners Slovenia (MIZS), Italy (MIUR), and France (RMP).

Acknowledgments: The authors also gratefully acknowledge the University of Ferrara for financial support (FAR funds). Thanks are also given to P. Formaglio for NMR spectroscopic experiments and to T. Bernardi for mass spectrometric experiments.

Conflicts of Interest: The authors declare no conflict of interest.

\section{References}

1. Tasić, Ž.Z.; Petrović Mihajlović, M.B.; Radovanović, M.B.; Antonijević, M.M. New trends in corrosion protection of copper. Chem. Pap. 2019, 73, 2103-2132. [CrossRef]

2. Ashassi-Sorkhabi, H.; Moradi-Alavian, S.; Esrafili, M.D.; Kazempour, A. Hybrid sol-gel coatings based on silanes-amino acids for corrosion protection of AZ91 magnesium alloy: Electrochemical and DFT insights. Prog. Org. Coat. 2019, 131, 191-202. [CrossRef]

3. Zaferani, S.; Peikari, M.; Zaarei, D.; Danaee, I.; Fakhraei, J.; Mohammadi, M. Using silane films to produce an alternative for chromate conversion coatings. Corrosion 2013, 69, 372-387. [CrossRef]

4. Bierwagen, G.; Shedlosky, T.J.; Stanek, K. Developing and testing a new generation of protective coatings for outdoor bronze sculpture. Prog. Org. Coat. 2003, 48, 289-296. [CrossRef]

5. Lamaka, S.V.; Shchukin, D.G.; Andreeva, D.V.; Zheludkevich, M.L.; Möhwald, H.; Ferreira, M.G.S. Sol-gel/polyelectrolyte active corrosion protection system. Adv. Funct. Mater. 2008, 18, 3137-3147. [CrossRef]

6. Zhang, F.; Ju, P.; Pan, M.; Zhang, D.; Huang, Y.; Li, G.; Li, X. Self-healing mechanisms in smart protective coatings: A review. Corros. Sci. 2018, 144, 74-88. [CrossRef]

7. Montemor, M.F. Functional and smart coatings for corrosion protection: A review of recent advances. Surf. Coat. Technol. 2014, 258, 17-37. [CrossRef]

8. Shchukin, D.G.; Zheludkevich, M.; Yasakau, K.; Lamaka, S.; Ferreira, M.G.S.; Möhwald, H.; Shchukin, D. Layer-by-layer assembled nanocontainers for self-healing corrosion protection. Adv. Mater. 2006, 18, 1672-1678. [CrossRef]

9. Jafari, A.; Hosseini, S.; Jamalizadeh, E. Investigation of smart nanocapsules containing inhibitors for corrosion protection of copper. Electrochim. Acta 2010, 55, 9004-9009. [CrossRef]

10. Mahmoudian, M.; Nozad, E.; Kochameshki, M.G.; Enayati, M. Preparation and investigation of hybrid self-healing coatings containing linseed oil loaded nanocapsules, potassium ethyl xanthate and benzotriazole on copper surface. Prog. Org. Coat. 2018, 120, 167-178. [CrossRef]

11. Zheludkevich, M.L.; Poznyak, S.K.; Rodrigues, L.M.; Raps, D.; Hack, T.; Dick, L.F.; Nunes, T.; Ferreira, M.G.S. Active protection coatings with layered double hydroxide nanocontainers of corrosion inhibitor. Corros. Sci. 2010, 52, 602-611. [CrossRef] 
12. Szejtli, J. Introduction and general overview of cyclodextrin chemistry. Chem. Rev. 1998, 98, $1743-1754$. [CrossRef]

13. Hedges, A.R. Industrial applications of cyclodextrins. Chem. Rev. 1998, 98, 2035-2044. [CrossRef]

14. Uekama, K.; Hirayama, F.; Irie, T. Cyclodextrin drug carrier systems. Chem. Rev. 1998, 98, 2045-2076. [CrossRef]

15. Del Valle, E.M.M. Cyclodextrins and their uses: A review. Process Biochem. 2004, 39, 1033-1046. [CrossRef]

16. Li, S.; Purdy, W.C. Cyclodextrins and their applications in analytical chemistry. Chem. Rev. 1992, 92, 1457-1470. [CrossRef]

17. Takahashi, K. Organic reactions mediated by cyclodextrins. Chem. Rev. 1998, 98, 2013-2034. [CrossRef]

18. De Souza, T.M.; Cordeiro, R.F.; Viana, G.M.; Aguiar, L.C.; De Senna, L.F.; Malta, L.F.B.; D’Elia, E.; D'Elia, E. Inclusion compounds of dibenzylthiourea with hydroxypropylated-cyclodextrins for corrosion protection of carbon steel in acidic medium. J. Mol. Struct. 2016, 1125, 331-339. [CrossRef]

19. Casaletto, M.P.; Figà, V.; Privitera, A.; Mazzaglia, A.; Scala, A.; Zagami, R. Sustainable corrosion inhibition of Copper-based alloys by smart $\beta$-Cyclodextrin/Benzotriazole complexes. In Proceedings of the 5th European Cyclodextrin Conference, Lisbon, Portugal, 3-6 October 2017.

20. Khramov, A.; Voevodin, N.; Balbyshev, V.; Donley, M. Hybrid organo-ceramic corrosion protection coatings with encapsulated organic corrosion inhibitors. Thin Solid Films 2004, 447, 549-557. [CrossRef]

21. Khramov, A.N.; Voevodin, N.N.; Balbyshev, V.N.; Mantz, R.A. Sol-gel-derived corrosion-protective coatings with controllable release of incorporated organic corrosion inhibitors. Thin Solid Films 2006, 514, 174-181. [CrossRef]

22. Amiri, S.; Rahimi, A. Anticorrosion behavior of cyclodextrins/inhibitor nanocapsule-based self-healing coatings. J. Coat. Technol. Res. 2016, 13, 1095-1102. [CrossRef]

23. Altin, A.; Rohwerder, M.; Erbe, A. Cyclodextrins as carriers for organic corrosion inhibitors in organic coatings. J. Electrochem. Soc. 2017, 164, C128-C134. [CrossRef]

24. Varvara, S.; Bostan, R.; Bobis, O.; Găină, L.; Popa, F.; Mena, V.; Souto, R.M. Propolis as a green corrosion inhibitor for bronze in weakly acidic solution. Appl. Surf. Sci. 2017, 426, 1100-1112. [CrossRef]

25. Verma, C.; Ebenso, E.E.; Bahadur, I.; Quraishi, M. An overview on plant extracts as environmental sustainable and green corrosion inhibitors for metals and alloys in aggressive corrosive media. J. Mol. Liq. 2018, 266, 577-590. [CrossRef]

26. Marzorati, S.; Verotta, L.; Trasatti, S.P. Green corrosion inhibitors from natural sources and biomass wastes. Molecules 2019, 24, 48. [CrossRef]

27. Zucchi, F.; Trabanelli, G.; Fonsati, M. Tetrazole derivatives as corrosion inhibitors for copper in chloride solutions. Corros. Sci. 1996, 38, 2019-2029. [CrossRef]

28. Mihit, M.; Salghi, R.; Bazzi, L.; Hammouti, B.; Kertit, S.; El Issami, S.; Addi, E.A. A study of tetrazoles derivatives as corrosion inhibitors of copper in nitric acid. Pigment Resin Technol. 2006, 35, 151-157. [CrossRef]

29. Balbo, A.; Chiavari, C.; Martini, C.; Monticelli, C. Effectiveness of corrosion inhibitor films for the conservation of bronzes and gilded bronzes. Corros. Sci. 2012, 59, 204-212. [CrossRef]

30. Wolfe, J.; Grayburn, R. A review of the development and testing of Incralac lacquer. J. Am. Inst. Conserv. 2017, 56, 225-244. [CrossRef]

31. Aufray, M.; Balbo, A.; Benetti, F.; Bernardi, E.; Bignozzi, M.C.; Chiavari, C.; Esvan, J.; Gartner, N.; Grassi, V.; Josse, C.; et al. Protection of outdoor bronzes by eco-friendly and non-hazardous coatings based on silane and fluoropolymers: Results from the B-IMPACT project. In Proceedings of the Metal 2019, Neuchâtel, Switzerland, 2-6 September 2019; pp. 1-10.

32. Chiavari, C.; Balbo, A.; Bernardi, E.; Martini, C.; Bignozzi, M.; Abbottoni, M.; Monticelli, C.; Bignozzi, M. Protective silane treatment for patinated bronze exposed to simulated natural environments. Mater. Chem. Phys. 2013, 141, 502-511. [CrossRef]

33. Masi, G.; Balbo, A.; Esvan, J.; Monticelli, C.; Avila, J.; Robbiola, L.; Bernardi, E.; Bignozzi, M.; Asensio, M.; Martini, C.; et al. X-ray photoelectron spectroscopy as a tool to investigate silane-based coatings for the protection of outdoor bronze: The role of alloying elements. Appl. Surf. Sci. 2018, 433, 468-479. [CrossRef]

34. Chiavari, C.; Bernardi, E.; Balbo, A.; Monticelli, C.; Raffo, S.; Bignozzi, M.; Martini, C.; Bignozzi, M. Atmospheric corrosion of fire-gilded bronze: Corrosion and corrosion protection during accelerated ageing tests. Corros. Sci. 2015, 100, 435-447. [CrossRef]

35. Wu, D.H.; Chen, A.D.; Johnson, C.S., Jr. An improved diffusion-ordered spectroscopy experiment incorporating bipolar-gradient pulses. J. Magn. Reson. Ser. A 1995, 115, 260-264. [CrossRef] 
36. Fielding, L. Determination of association constants $\left(K_{\mathrm{a}}\right)$ from solution NMR data. Tetrahedron 2000, 56, 6151-6170. [CrossRef]

37. Frassineti, C.; Ghelli, S.; Gans, P.; Sabatini, A.; Moruzzi, M.S.; Vacca, A. Nuclear magnetic resonance as a tool for determining protonation constants of natural polyprotic bases in solution. Anal. Biochem. 1995, 231, 374-382. [CrossRef]

38. Zucchi, F.; Frignani, A.; Grassi, V.; Trabanelli, G.; DalColle, M. The formation of a protective layer of 3-mercapto-propyl-trimethoxy-silane on copper. Corros. Sci. 2007, 49, 1570-1583. [CrossRef]

39. Chiavari, C.; Balbo, A.; Bernardi, E.; Martini, C.; Zanotto, F.; Vassura, I.; Bignozzi, M.; Monticelli, C.; Bignozzi, M. Organosilane coatings applied on bronze: Influence of UV radiation and thermal cycles on the protectiveness. Prog. Org. Coat. 2015, 82, 91-100. [CrossRef]

40. Masi, G.; Josse, C.; Esvan, J.; Chiavari, C.; Bernardi, E.; Martini, C.; Bignozzi, M.C.; Monticelli, C.; Zanotto, F.; Balbo, A.; et al. Evaluation of the protectiveness of an organosilane coating on patinated Cu-Si-Mn bronze for contemporary art. Prog. Org. Coat. 2019, 127, 286-299. [CrossRef]

41. Stern, M.; Geary, A.L. Electrochemical polarization I. A theoretical analysis of the shape of polarization curves. J. Electrochem. Soc. 1957, 104, 56-63. [CrossRef]

42. Pessine, F.B.T.; Calderini, A.; Alexandrino, G.L. Review: Cyclodextrin inclusion complexes probed by NMR techniques. Magn. Reson. Spectr. 2012, 2012, 237-264.

43. Kfoury, M.; Auezova, L.; Greige-Gerges, H.; Ruellan, S.; Fourmentin, S. Cyclodextrin, an efficient tool for trans-anethole encapsulation: Chromatographic, spectroscopic, thermal and structural studies. Food Chem. 2014, 164, 454-461. [CrossRef]

44. Schneider, H.-J.; Hacket, F.; Rüdiger, V.; Ikeda, H. NMR studies of cyclodextrins and cyclodextrin complexes. Chem. Rev. 1998, 98, 1755-1786. [CrossRef]

45. Bothner-By, A.A.; Stephens, R.L.; Lee, J.; Warren, C.D.; Jeanloz, R.W. ChemInform Abstract: Structure determination of a tetrasaccharide: transient nuclear overhauser effects in the rotating frame. Chem. Inf. 1984, 15, 811-813. [CrossRef]

46. Holm, R.; Østergaard, J.; Schőnbeck, C.; Jensen, H.; Shi, W.; Peters, G.H.; Westh, P. Determination of stability constants of tauro- and glycoconjugated bile salts with the negatively charged sulfobutylether- $\beta$-cyclodextrin: Comparison of affinity capillary electrophoresis and isothermal titration calorimetry and thermodynamic analysisof the interaction. J. Incl. Phenom. Macrocycl. Chem. 2014, 78, 185-194. [CrossRef]

47. Cameron, K.S.; Fielding, L. NMR diffusion coefficient study of steroid-cyclodextrin inclusion complexes. Magn. Reson. Chem. 2002, 40, S106-S109. [CrossRef]

48. Rymdén, R.; Carlfors, J.; Stilbs, P. Substrate binding to cyclodextrins in aqueous solution: A multicomponent self-diffusion study. J. Incl. Phenom. Macrocycl. Chem. 1983, 1, 159-167.

49. Mayzel, O.; Cohen, Y. Diffusion coefficients of macrocyclic complexes using the PGSE NMR technique: Determination of association constants. J. Chem. Soc. Chem. Commun. 1994, 16, 1901-1902. [CrossRef]

50. Wimmer, R.; Aachmann, F.L.; Larsen, K.L.; Petersen, S.B. NMR diffusion as a novel tool for measuring the association constant between cyclodextrin and guest molecules. Carbohydr. Res. 2002, 337, 841-849. [CrossRef]

51. Cameron, K.S.; Fielding, L. NMR diffusion spectroscopy as a measure of host-guest complex association constants and as a probe of complex size. J. Org. Chem. 2001, 66, 6891-6895. [CrossRef]

52. Šmejkalová, D.; Piccolo, A. Host-guest interactions between 2,4-dichlorophenol and humic substances as evaluated by ${ }^{1} \mathrm{H}$ NMR relaxation and diffusion ordered spectroscopy. Environ. Sci. Technol. 2008, 42, 8440-8445. [CrossRef]

53. Ye, X.; Xin, X.; Zhu, J.; Xue, Z. Coordination compound films of 1-phenyl-5-mercaptotetrazole on copper surface. Appl. Surf. Sci. 1998, 135, 307-317. [CrossRef]

54. Monticelli, C.; Balbo, A.; Esvan, J.; Chiavari, C.; Martini, C.; Zanotto, F.; Marvelli, L.; Robbiola, L. Evaluation of 2-(salicylideneimino) thiophenol and other Schiff bases as bronze corrosion inhibitors by electrochemical techniques and surface analysis. Corros. Sci. 2019, 148, 144-158. [CrossRef]

(C) 2019 by the authors. Licensee MDPI, Basel, Switzerland. This article is an open access article distributed under the terms and conditions of the Creative Commons Attribution (CC BY) license (http://creativecommons.org/licenses/by/4.0/). 